\title{
Platelet-Derived Growth Factor and Transforming Growth Factor $\beta 1$ Regulate ARDS-Associated Lung Fibrosis Through Distinct Signaling Pathways
}

\author{
Xingqi Deng Kun Jin Yanyan Li Wei Gu Mei Liu Ling Zhou \\ Department of Emergency Medicine, the Central Hospital of Minhang District, Fudan University, \\ Shanghai, China
}

\section{Key Words}

Acute lung injury (ALI) - Acute respiratory distress syndrome (ARDS) - SMAD3 - Plateletderived growth factor (PDGF) • Transforming growth factor $\beta 1$ (TGF $\beta 1) \cdot p 38$ MAPK • p42/p44 MAPK $•$ Collagen I $\bullet \alpha$-smooth muscle actin $(\alpha$-SMA)

\begin{abstract}
Background/Aims: Severe acute lung injury (ALI) often develops into acute respiratory distress syndrome (ARDS). Previous studies have shown that platelet-derived growth factor (PDGF) and transforming growth factor $\beta 1$ (TGF $\beta 1$ ) participate in the pathogenesis of ARDS by stimulation of fibroblast proliferation, leading to the development of pulmonary fibrosis. However, the exact pathways downstream of PDGF and TGF $\beta$ receptor signaling have not been completely elucidated. Method: We treated human lung fibroblasts (HLF) with PDGF, or TGF $\beta 1$, or combined, and examined the activation of p38 MAPK, p42/p44 MAPK and SMAD3. We used a specific inhibitor PD98059 to antagonize phosphorylation of p42/p44 MAPK, or used a specific inhibitor SN203580 to antagonize phosphorylation of p38 MAPK, or used a specific inhibitor SIS3 to antagonize phosphorylation of SMAD3. We then examined the effects of these inhibitors on the activation of collagen I and $\alpha$-smooth muscle actin ( $\alpha$-SMA) induced by PDGF or TGF 31 stimulation. Results: PDGF activated p38 MAPK and p42/p44 MAPK, but not SMAD3 in HLF cells. TGFB1 activated p38 MAPK and SMAD3, but not p42/p44 MAPK in HLF cells. Activation of p38 MAPK by either PDGF or TGF $\beta 1$ induced $\alpha$-SMA but not collagen I in HLF cells, while activation of p42/p44 MAPK by PDGF induced collagen I but not $\alpha$-SMA in HLF cells. Activation of SMAD3 by TGF $\beta 1$ did not affect either collagen I or $\alpha$-SMA in HLF cells. Conclusion: PDGF and TGF $\beta 1$ regulate ARDS-associated lung fibrosis through distinct signaling pathway-mediated activation of fibrosis-related proteins. Treatments with both PDGF and TGF $\beta 1$ antagonists may result in a better anti-fibrotic outcome for ALI-induced lung fibrosis.




\section{Cellular Physiology Cell Physiol Biochem 2015;36:937-946 \begin{tabular}{l|l} 
and Biochemistry Published online: June 12, 2015 & $\begin{array}{l}\text { C) 2015 S. Karger AG, Basel } \\
\text { www.karger.com/cpb }\end{array}$ \\
\hline
\end{tabular} \\ Deng et al.: PDGF and TGFB1 Regulate ARDS-Associated LF}

\section{Introduction}

Acute lung injury (ALI) is a common clinical lung disease, and severe ALI often develops into acute respiratory distress syndrome (ARDS), which is a devastating clinical syndrome characterized by non-cardiogenic pulmonary edema, respiratory distress and hypoxemia [13]. Although the ARDS-associated mortality has decreased in the last decade, still about half of the patients die, while the survivors suffer from significant physical and psychological impairments [1-3]. Recently, the Berlin definition brought an update over the previous definitions for ALI and ARDS [1-3]. In the new definition, data over the first 24hours are now applied for reclassification of the severity of the disease, while compliance to stratify each oxygenation category is also used for the definition [1-3].

The ALI induces co-occurrence of damage to the alveolar capillary membrane, edema formation and repair of the alveolar-capillary membrane with a varying degree of fibrosis [4-10]. Of note, previous studies have indicated that changes in various cytokines such as platelet-derived growth factor (PDGF) and transforming growth factor $\beta 1$ (TGF $\beta 1$ ) are involved in these processes and play critical roles [11-15].

PDGF is produced by activated platelets, smooth muscle cells, activated macrophages and endothelial cells $[16,17]$. PDGF is a potent mitogen for cells of mesenchymal origin, including smooth muscle cells and glial cells $[16,17]$. In particular, it plays a significant role in angiogenesis $[16,17]$. Moreover, PDGF is a required element in cellular division for fibroblasts $[16,17]$. It has been shown that in monocytes-macrophages and fibroblasts, exogenously administered PDGF stimulates chemotaxis, proliferation, and gene expression and significantly augmented the influx of inflammatory cells and fibroblasts, accelerating extracellular matrix and collagen formation and thus reducing the time for the healing process to occur $[16,17]$. PDGF binds to its receptor (a receptor tyrosine kinase (RTK)) on the ligand binding pocket located within the second and third immunoglobulin domains $[16,17]$. Upon activation by PDGF, the receptor was phosphorylated to activate downstream signaling cascades, among which mitogen-activated protein kinase (MAPK) has been shown to regulate fibroblast growth [18-25].

TGF $\beta 1$ is a ligand for TGF $\beta$ receptor. TGF- $\beta$ receptor signaling plays a central role in mammalian tissue development, homeostasis, and disease [26-28]. In short, a TGF- $\beta$ ligand binds to the serine/threonine kinase receptor TGF $\beta$ Receptor Type 2, which phosphorylates and activates TGF- $\beta$ Receptor Type 1 [26-28]. This phosphorylation leads to phosphorylation of receptor-regulated R-SMAD molecules, SMAD2 and SMAD3, followed by nuclear translocation and transcriptional SMAD activity [26-28]. Activation of these downstream effectors is inhibited by SMAD6 and/or SMAD7 [26-28]. Moreover, TGF- $\beta$ receptor signaling can be conducted through SMAD-independent pathway, e.g. p38 MAPK [29-41].

Although previous studies have shown that PDGF and TGF $\beta 1$ participate in the pathogenesis of ARDS by stimulation of fibroblast proliferation, leading to the development of pulmonary fibrosis, the exact pathways downstream of PDGF and TGF $\beta$ receptor signaling have not been completely elucidated.

Here, we addressed these unsolved questions by treating human lung fibroblasts (HLF) with PDGF, or TGF $\beta 1$, or combined, followed by examination of the activation of $\mathrm{p} 38$ MAPK, p42/p44 MAPK and SMAD3. We used a specific inhibitor PD98059 to antagonize phosphorylation of p42/p44 MAPK, or used a specific inhibitor SN203580 to antagonize phosphorylation of p38 MAPK, or used a specific inhibitor SIS3 to antagonize phosphorylation of SMAD3. We then examined the effects of these inhibitors on the activation of collagen I and $\alpha$-smooth muscle actin ( $\alpha$-SMA) induced by PDGF or TGF $\beta 1$ stimulation. We found that PDGF activated p38 MAPK and p42/p44 MAPK, but not SMAD3 in HLF cells. TGF $\beta 1$ activated p38 MAPK and SMAD3, but not p42/p44 MAPK in HLF cells. Activation of p38 MAPK by either PDGF or TGF $\beta 1$ induced $\alpha$-SMA but not collagen I in HLF cells, while activation of p42/p44 MAPK by PDGF induced collagen I but not $\alpha$-SMA in HLF cells. Activation of SMAD3 by TGF $\beta 1$ did not affect either collagen I or $\alpha$-SMA in HLF cells. These data thus suggest that PDGF and TGFB1 regulate ARDS-associated lung fibrosis through distinct signaling pathway-mediated 


\section{Cellular Physiology Cell Physiol Biochem 2015;36:937-946 \\ \begin{tabular}{l|l|l}
\hline DOI: 10.1159/000430268 & (C)15 S. Karger AG, Basel
\end{tabular} \\ \begin{tabular}{l|l} 
and Biochemistry Published online: June 12, 2015 & www.karger.com/cpb \\
\hline
\end{tabular} \\ Deng et al.: PDGF and TGF $\beta 1$ Regulate ARDS-Associated LF}

activation of fibrosis-related proteins. Treatments with both PDGF and TGF $\beta 1$ antagonists may result in a better anti-fibrotic outcome for ALI-induced lung fibrosis.

\section{Materials and Methods}

Cell lines and reagents

Human lung fibroblasts (HLF) IMR-90 was derived by W.W. Nichols [42] and associates from the lungs of a 16-week female fetus. This cell cline was purchased from ATCC (American Type Culture Collection, Manassas, VA, USA). IMR-90 cells were cultured in ATCC-formulated Eagle's Minimum Essential Medium, Catalog No. 30-2003, with 10\% fetal bovine serum (FBS, Invitrogen, St. Louis, MO, USA). PDGF (used at a

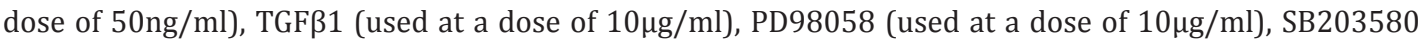
(used at a dose of $1 \mu \mathrm{g} / \mathrm{ml}$ ) and SIS3 (used at a dose of $2 \mu \mathrm{g} / \mathrm{ml}$ ) were all purchased from Sigma-Aldrich (St. Louis, MO, USA).

\section{$R T-q P C R$}

RNA was extracted from cultured cells with RNeasy (Qiagen, Hilden, Germany). cDNA synthesis was performed by reserve transcription. Quantitative PCR (RT-qPCR) were performed in duplicates with QuantiTect SYBR Green PCR Kit (Qiagen). All primers were purchased from Qiagen. Values of genes were first normalized against $\alpha$-tubulin, and then compared to the controls.

Western blot

The protein from the cultured cells was extracted using RIPA lysis buffer (1\% NP40, 0.1\% Sodium dodecyl sulfate (SDS), $100 \mu \mathrm{g} / \mathrm{ml}$ phenylmethylsulfonyl fluoride, $0.5 \%$ sodium deoxycholate, in PBS) on ice. The supernatants were collected after centrifugation at $12000 \times \mathrm{g}$ at $4^{\circ} \mathrm{C}$ for $20 \mathrm{~min}$. Protein concentration was determined using a BCA protein assay kit (Bio-rad, China), and whole lysates were mixed with $4 \times$ SDS loading buffer (125mmol/l Tris-HCl, 4\% SDS, 20\% glycerol, 100mmol/l Dithiothreitol (DTT), and 0.2\% bromophenol blue) at a ratio of $1: 3$. Samples were heated at $100{ }^{\circ} \mathrm{C}$ for $5 \mathrm{~min}$ and were separated on SDSpolyacrylamide gels. The separated proteins were then transferred to a PVDF membrane. The membrane blots were first probed with a primary antibody. After incubation with horseradish peroxidase-conjugated second antibody, autoradiograms were prepared using the enhanced chemiluminescent system to visualize the protein antigen. The signals were recorded using X-ray film. Primary antibodies were anti-p38 MAPK, anti-phosphorylated p38 MAPK (p-p38 MAPK), anti-p42/p44 MAPK, anti-phosphorylated p42/p44 MAPK (p-p42/p44 MAPK), anti-SMAD3, anti-phosphorylated SMAD3 (pSMAD3), anti-collagen I, anti- $\alpha$-SMA and $\alpha$-tubulin (all purchased from Cell Signaling, St Louis, MO, USA). $\alpha$-tubulin was used as a protein loading control for collagen I and $\alpha$-SMA. An un-phosphorylated protein was used as a protein loading control for the corresponding phosphorylated protein. Secondary antibody is HRP-conjugated anti-rabbit (Jackson ImmunoResearch Labs, West Grove, PA, USA). Images shown in the figure were representative from 5 repeats. Densitometry of Western blots was quantified with NIH ImageJ software. The protein levels were first normalized to loading controls, and then normalized to experimental controls.

\section{Statistical analysis}

All statistical analyses were carried out using the SPSS 18.0 statistical software package. All values are depicted as mean \pm standard deviation from 5 individuals and are considered significant if $\mathrm{p}<0.05$. All data were statistically analyzed using one-way ANOVA with a Bonferoni correction, followed by a Fisher's exact test, as necessary.

\section{Results}

PDGF activates p38 MAPK and p42/p44 MAPK, while TGFß1 activates p38 MAPK and SMAD3 in HLF cells

We treated human lung fibroblast (HLF) cells with PDGF, or TGF $\beta 1$, or combined, and examined the activation of p38 MAPK, p42/p44 MAPK and SMAD3 by Western blot.

We found that PDGF activated p38 MAPK in HLF cells, by representative immunoblots (Fig. 1A), and by quantification (Fig. 1B). Moreover, PDGF also activated p42/p44 MAPK in HLF cells, by representative immunoblots (Fig. 1A), and by quantification (Fig. 1C). However, 


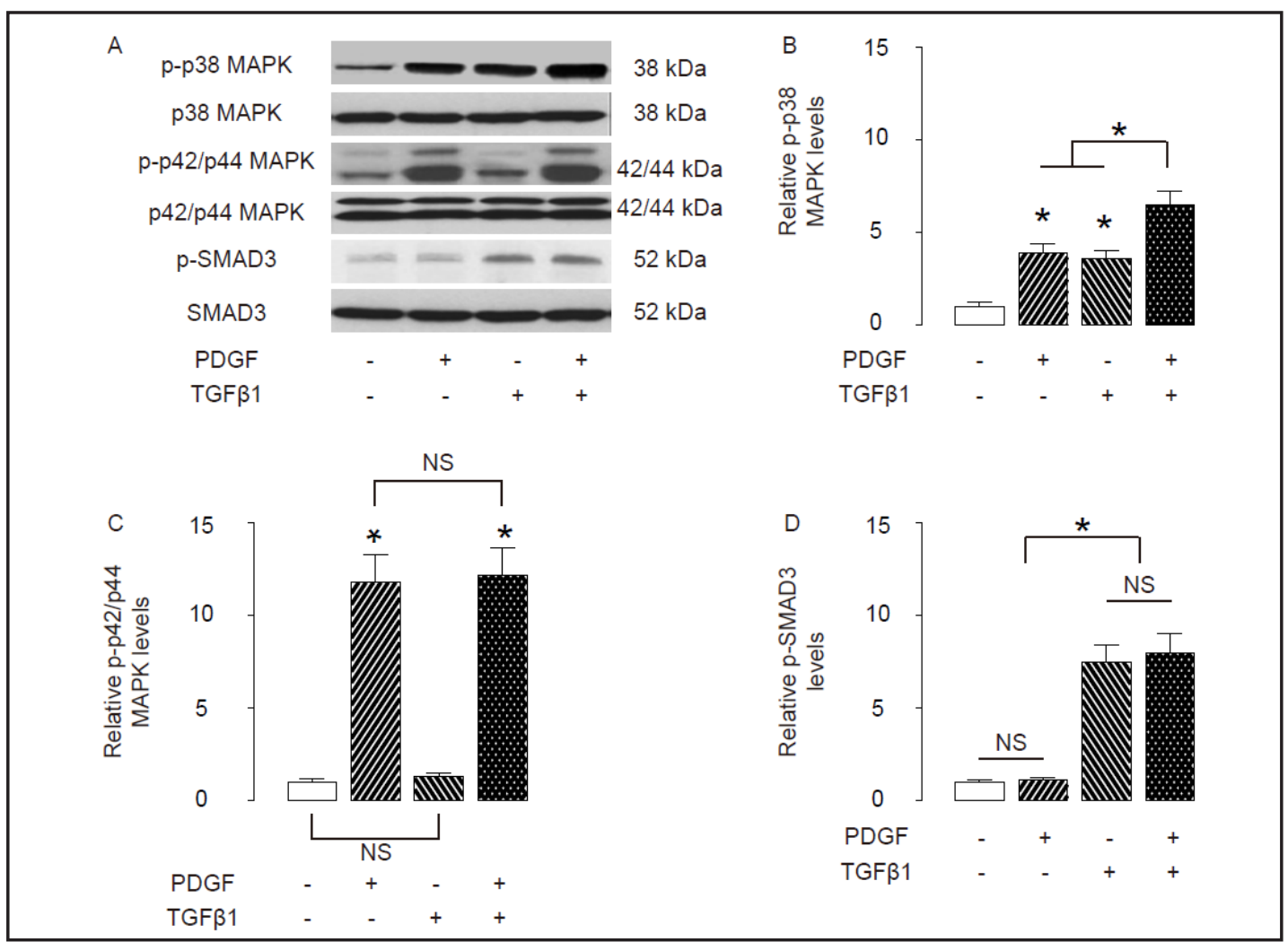

Fig. 1. PDGF activates $\mathrm{p} 38 \mathrm{MAPK}$ and $\mathrm{p} 42 / \mathrm{p} 44 \mathrm{MAPK}$, while TGF 31 activates p38 MAPK and SMAD3 in HLF cells. We treated human lung fibroblast (HLF) cells with PDGF, or TGF $\beta 1$, or combined, and examined the activation of p38 MAPK, p42/p44 MAPK and SMAD3 by Western blot. (A) Representative immunoblots (BD) Quantification for levels of p-p38 MAPK (B), p-p42/p44 MAPK (C) and p-SMAD3 (D). *p<0.05. NS: nonsignificant. $\mathrm{N}=5$. Statistics: one-way ANOVA, followed by a Fisher' Exact Test.

PDGF did not affect phosphorylation of SMAD3 in HLF cells, by representative immunoblots (Fig. 1A), and by quantification (Fig. 1D).

We also found that TGF 31 activated p38 MAPK in HLF cells, by representative immunoblots (Fig. 1A), and by quantification (Fig. 1B). However, PDGF did not affect phosphorylation of p42/p44 MAPK in HLF cells, by representative immunoblots (Fig. 1A), and by quantification (Fig. 1C). In addition, TGF $\beta 1$ also activated SMAD3 in HLF cells, by representative immunoblots (Fig. 1A), and by quantification (Fig. 1D).

Since p38 MAPK was activated by either PDGF or TGF $\beta 1$, we examined whether combined PDGF and TGF $\beta 1$ may further increase the activation of p38 MAPK. We found that combined PDGF and TGF $\beta 1$ significantly increased the activation of p38 MAPK in HLF cells, compared to either PDGF or TGF $\beta 1$ alone, by representative immunoblots (Fig. 1A), and by quantification (Fig. 1B). Moreover, combined PDGF and TGF $\beta 1$ did not further increased the activation of p42/p44 MAPK in HLF cells by PDGF alone (Fig. 1A, C), or the activation of SMAD3 by TGF $\beta 1$ alone (Fig. 1A, D).

Together, these data suggest that PDGF activates p38 MAPK and p42/p44 MAPK, while TGF $\beta 1$ activates p38 MAPK and SMAD3 in HLF cells.

PDGF-induced activation of 38 MAPK upregulates $\alpha$-SMA, while PDGF-induced activation of $\mathrm{p} 42 / \mathrm{p} 44 \mathrm{MAPK}$ upregulates collagen I in HLF cells

In order to figure out how PDGF may regulate different fibrosis-associated proteins collagen I and $\alpha$-SMA through p38 MAPK and p42/p44 MAPK signaling, we used a specific inhibitor PD98059 to antagonize phosphorylation of p42/p44 MAPK, or used a specific 
Fig. 2. PDGF-induced activation of p38 MAPK upregulates $\alpha$-SMA, while PDGF-induced activation of $\mathrm{p} 42 / \mathrm{p} 44$ MAPK upregulates collagen I in HLF cells. In order to figure out how PDGF may regulate different fibrosis-associated proteins collagen I and $\alpha$-SMA through p38 MAPK and p42/p44 MAPK signaling, we used a specific inhibitor PD98059 to antagonize phosphorylation of p42/p44 MAPK, or used a specific inhibitor SB203580 to antagonize phosphorylation of p38 MAPK, in PDGF-treated HLF cells. (A) Representative immunoblots (BE) Quantification for protein levels of p-p38 MAPK (B), p-p42/p44 MAPK (C), Collagen I (D) and $\alpha$-SMA (E). (F-G) Quantification for mRNA levels of Collagen I (F) and $\alpha$-SMA (G). ${ }^{*} \mathrm{p}<0.05$. NS: Non-significant. $\mathrm{N}=5$. Statistics: oneway ANOVA, followed by a Fisher' Exact Test.
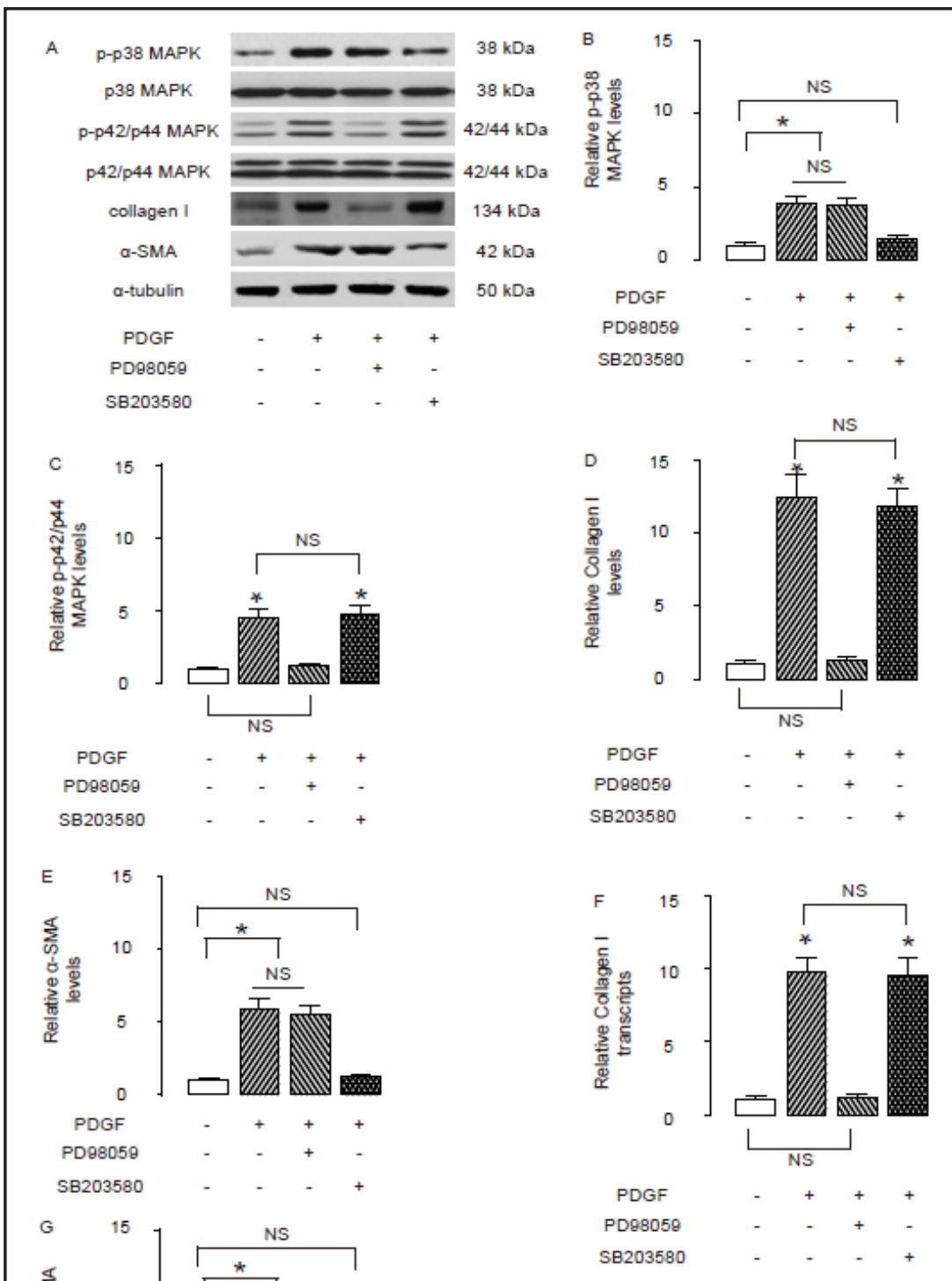

inhibitor SB203580 to antagonize phosphorylation of p38 MAPK, in PDGF-treated HLF cells. We confirm that SB203580 is a specific inhibitor for p38 MAPK phosphorylation, and does not affect p42/p44 MAPK phosphorylation, shown by representative immunoblots (Fig. 2A), and by quantification (Fig. 2B-C). We also confirm that PD98059 is a specific inhibitor for p42/p44 MAPK phosphorylation, and does not affect p38 MAPK phosphorylation, shown by representative immunoblots (Fig. 2A), and by quantification (Fig. 2B-C).

Interestingly, inhibition of PDGF-induced p38 MAPK phosphorylation by SB203580 significantly abolished the PDGF-stimulated activation of $\alpha$-SMA, but did not affect the PDGFstimulated activation of collagen I, by immunoblots (Fig. 2A, D-E) and by RT-qPCR (Fig. 2F-G). On the contrary, inhibition of PDGF-induced p42/p44 MAPK phosphorylation by PD98059 
Fig. 3. TGF $\beta 1$-induced activation of p38 MAPK upregulates $\alpha$-SMA, while TGF $\beta 1$-induced activation of SMAD3 does not affect either $\alpha$-SMA or collagen I in HLF cells. In order to figure out how TGF $\beta 1$ may regulate different fibrosis-associated proteins collagen I and $\alpha$-SMA through p38 MAPK and SMAD3 signaling, we used a specific inhibitor SIS3 to antagonize phosphorylation of SMAD3, or used a specific inhibitor SB203580 to antagonize phosphorylation of p38 MAPK, in TGF 31 -treated HLF cells. (A) Representative immunoblots (B-E) Quantification for protein levels of p-p38 MAPK (B), p-SMAD3 (C), Collagen I (D) and $\alpha$-SMA (E). (F-G) Quantification for mRNA levels of Collagen I (F) and $\alpha$-SMA (G). ${ }^{*} \mathrm{p}<0.05$. NS: non-significant. $\mathrm{N}=5$. Statistics: one-way ANOVA, followed by a Fisher' Exact Test.

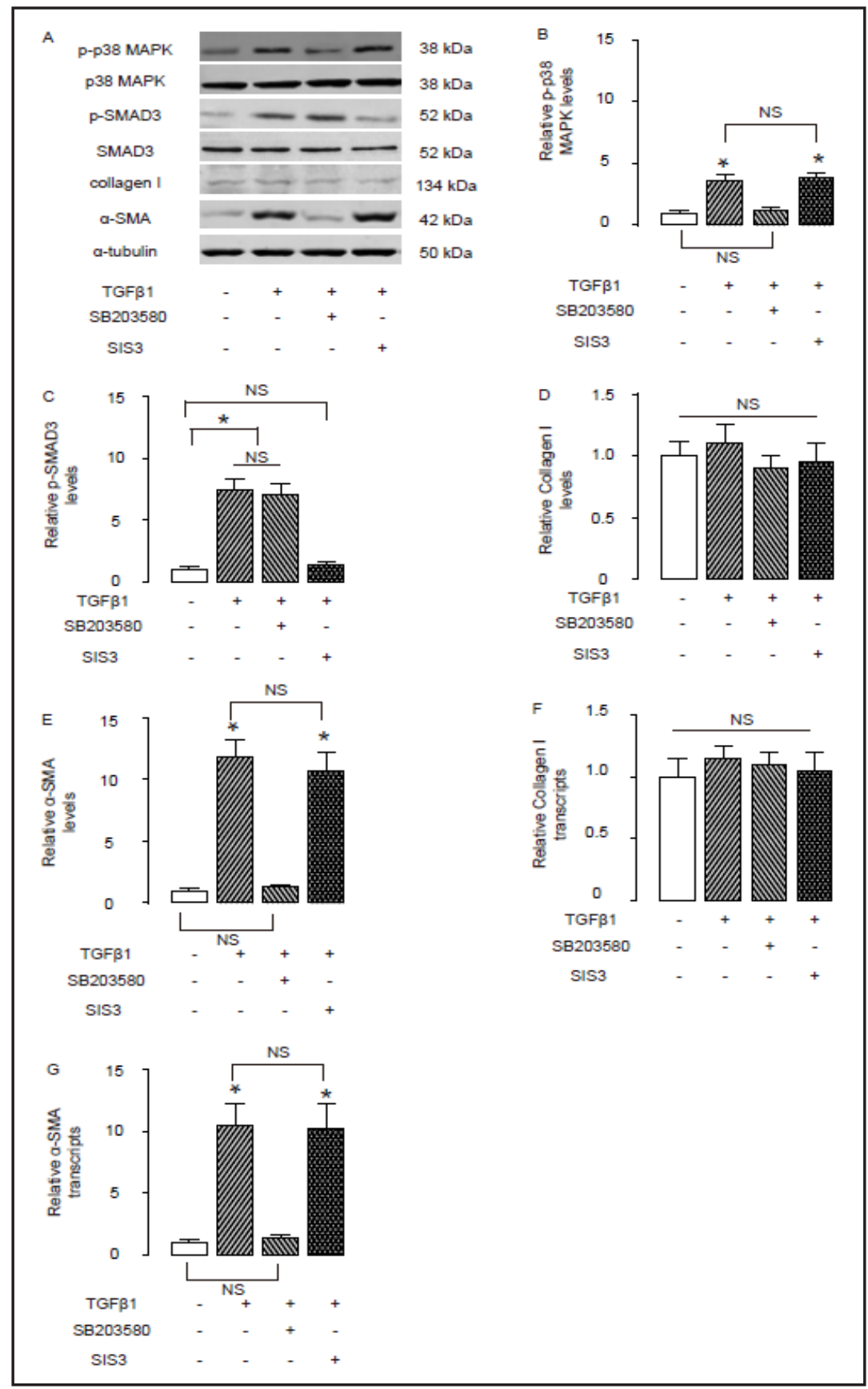

significantly abolished the PDGF-stimulated activation of collagen I, but did not affect the PDGF-stimulated activation of $\alpha$-SMA, by immunoblots (Fig. 2A, D-E) and by RT-qPCR (Fig. 2F-G).

Together, these data suggest that PDGF-induced activation of p38 MAPK upregulates $\alpha$-SMA, while PDGF-induced activation of p42/p44 MAPK upregulates collagen I in HLF cells.

TGFB1-induced activation of p38 MAPK upregulates $\alpha$-SMA, while TGFß1-induced activation of SMAD3 does not affect either $\alpha$-SMA or collagen I in HLF cells

In order to figure out how TGF $\beta 1$ may regulate different fibrosis-associated proteins collagen I and $\alpha$-SMA through p38 MAPK and SMAD3 signaling, we used a specific inhibitor SIS3 to antagonize phosphorylation of SMAD3, or used a specific inhibitor SB203580 to antagonize phosphorylation of p38 MAPK, in TGFß1-treated HLF cells. We confirm that KARGER 


\section{Cellular Physiology Cell Physiol Biochem 2015;36:937-946 \begin{tabular}{|c|c|c|}
\hline DOI: 10.1159/000430268 & O 2015 S. Karger AG, Basel
\end{tabular}

Fig. 4. Schematic of the model. PDGF activated $\mathrm{p} 38$ MAPK and p42/p44 MAPK, but not SMAD3 in HLF cells. TGF 31 activated p38 MAPK and SMAD3, but not $\mathrm{p} 42 / \mathrm{p} 44$ MAPK in HLF cells. Activation of p38 MAPK by either PDGF or TGF $\beta 1$ induced $\alpha$-SMA but not collagen I in HLF cells, while activation of p42/p44 MAPK by PDGF induced collagen I but not $\alpha$-SMA in HLF cells. Activation of SMAD3 by TGF $\beta 1$ did not affect either collagen I or $\alpha$-SMA in HLF cells.

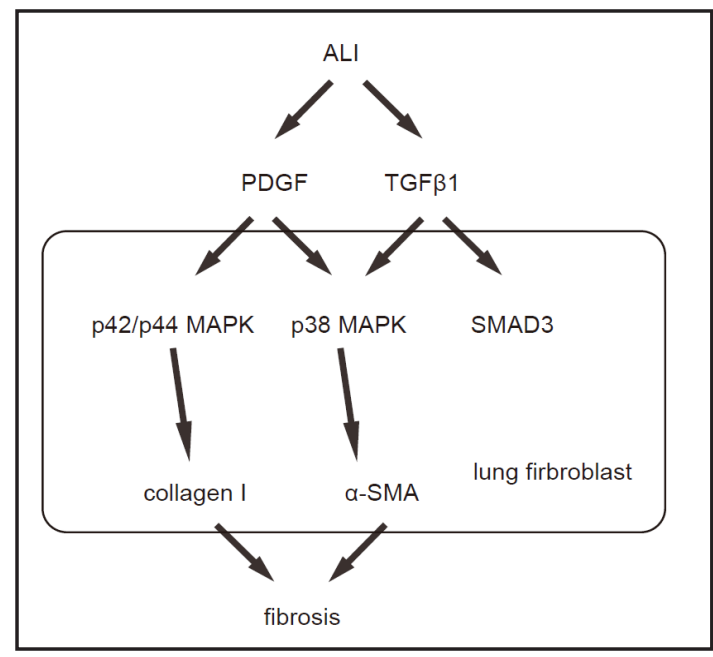

SB203580 is a specific inhibitor for p38 MAPK phosphorylation, and does not affect SMAD3 phosphorylation, shown by representative immunoblots (Fig. 3A), and by quantification (Fig. 3B-C). We also confirm that SIS3 is a specific inhibitor for SMAD3 phosphorylation, and does not affect p38 MAPK phosphorylation, shown by representative immunoblots (Fig. 3A), and by quantification (Fig. 3B-C).

Interestingly, inhibition of TGF $\beta 1$-induced p38 MAPK phosphorylation by SB203580 significantly abolished the TGF $\beta 1$-stimulated activation of $\alpha$-SMA, and did not affect the collagen I levels, by immunoblots (Fig. 3A, D-E) and by RT-qPCR (Fig. 3F-G). However, inhibition of TGF $\beta 1$-induced SMAD3 phosphorylation by SIS3 did not affect either collagen I, or $\alpha$-SMA levels, by immunoblots (Fig. 3A, D-E) and by RT-qPCR (Fig. 3F-G).

Together, these data suggest that TGF $\beta 1$-induced activation of p38 MAPK upregulates $\alpha$-SMA, while TGF $\beta 1$-induced activation of SMAD3 does not affect either $\alpha$-SMA or collagen I in HLF cells. Moreover, these data are consistent with data from PDGF, and suggest a model in which PDGF and TGF $\beta 1$ regulate ARDS-associated lung fibrosis through distinct signaling pathway-mediated activation of fibrosis-related proteins. Thus, this model was summarized in a schematic (Fig. 4).

\section{Discussion}

Fibrotic lung develops concomitantly with severe ALI and ARDS, and the prevention of these lethal diseases requires efficient treatments to the pivotal targets [4-8]. The underlying mechanism of lung fibrosis involves the proliferation of mesenchymal cells possessing a myofibroblast phenotype and the subsequent deposition of collagen and other extracellular matrix proteins by these cells leading to progressive scarring and loss of organ function [4-8]. In general, fibrogenesis is a response to tissue injury and many of the same factors that mediate tissue repair also promote a fibrogenesis [4-8]. Therefore, understanding the associated factors in the pathogenesis is paramount to developing treatment strategies for fibrotic diseases. Several polypeptide mediators are central to the fibrotic process, including PDGF and TGF 31 [4-8, 11-14]. They play coordinated but differential roles in myofibroblast proliferation and fibrogenesis-related collagen deposition [4-8, 11-14]. However, the exact molecular details are not clear.

Here, we analyzed p38 and p42/p44 MAPK as well as SMAD3 activation by PDGF and TGFß1 in HLF cells. We found that PDGF activates p38 MAPK and p42/p44 MAPK, but not SMAD3 in HLF cells. TGF 31 activates p38 MAPK and SMAD3, but not p42/p44 MAPK in HLF cells. Thus, PDGF and TGF $\beta 1$ share a common pathway of p38 MAPK, but have unique signaling for their own. Moreover, activation of p38 MAPK by either PDGF or TGF $\beta 1$ induced $\alpha$-SMA but not collagen I in HLF cells, while activation of p42/p44 MAPK by PDGF induced 


\section{Cellular Physiology Cell Physiol Biochem 2015;36:937-946 \begin{tabular}{|c|l|}
\hline DOI: 10.1159/000430268 & O 2015 S. Karger AG, Basel
\end{tabular} and Biochemistry Published online: June 12, 2015 www.karger.com/cpb \\ Deng et al.: PDGF and TGF $\beta 1$ Regulate ARDS-Associated LF}

collagen I but not $\alpha$-SMA in HLF cells. Activation of SMAD3 by TGF $\beta 1$ did not affect either collagen I or $\alpha$-SMA in HLF cells. These data well explain the coordinating effects of PDGF and TGF $\beta 1$ in the development of lung fibrosis after ALI or ARDS, and also provide the molecular bases for the suboptimal therapeutic outcome targeting either molecule. Thus, a strategy to inhibit both signaling pathways may be crucial for an effective treatment.

In this study, we did not find a direct effect of an activated SMAD signaling on the activation of either collagen I or $\alpha$-SMA. However, SMAD signaling is well-known for cellcycle control in many types of cells [43-49]. Hence, the downstream effect of SMAD3 in this model may be related directly to cell proliferation, apoptosis or autophagy [43-49], but not directly associate with fibrogenesis-related events, e.g. transformation of fibroblasts into myofibroblasts through $\alpha$-SMA, or direct collagen deposit in the lung parenchyma evident by collagen I as a marker. Future experiments may be applied to address these unsolved questions. To exclude a possibility that the current results are cell-line-dependent, we also checked several other lines and got essentially same result. Hence, our findings may be generally applicable.

In summary, we show that PDGF and TGF $\beta 1$ regulate ARDS-associated lung fibrosis through distinct signaling pathway-mediated activation of fibrosis-related proteins. Treatments with both PDGF and TGF $\beta 1$ antagonists may result in a better anti-fibrotic outcome for ALI-induced lung fibrosis.

\section{Acknowledgement}

This work was supported by the program for Development of Key Disciplines of Shanghai (series number: ZK2012A23).

\section{Disclosure Statement}

The authors have declared that no conflict of interest exists.

\section{Reference}

1 Kangelaris KN, Calfee CS, May AK, Zhuo H, Matthay MA, Ware LB: Is there still a role for the lung injury score in the era of the berlin definition ards? Ann Intensive Care 2014;4:4.

2 Khemani RG, Wilson DF, Esteban A, Ferguson ND: Evaluating the berlin definition in pediatric ards. Intensive Care Med 2013;39:2213-2216.

3 Thompson BT, Matthay MA: The berlin definition of ards versus pathological evidence of diffuse alveolar damage. Am J Respir Crit Care Med 2013;187:675-677.

4 Chen W, Zheng G, Yang S, Ping W, Fu X, Zhang N, Wang DW, Wang J: Cyp2j2 and eets protect against oxidative stress and apoptosis in vivo and in vitro following lung ischemia/reperfusion. Cell Physiol Biochem 2014;33:1663-1680.

5 Dhami R, He X, Schuchman EH: Acid sphingomyelinase deficiency attenuates bleomycin-induced lung inflammation and fibrosis in mice. Cell Physiol Biochem 2010;26:749-760.

6 Talebian L, Coutermarsh B, Channon JY, Stanton BA: Corr4a and vrt325 do not reduce the inflammatory response to p. Aeruginosa in human cystic fibrosis airway epithelial cells. Cell Physiol Biochem 2009;23:199-204.

7 Baudouin-Legros M, Hamdaoui N, Borot F, Fritsch J, Ollero M, Planelles G, Edelman A: Control of basal cftr gene expression by bicarbonate-sensitive adenylyl cyclase in human pulmonary cells. Cell Physiol Biochem 2008;21:75-86.

8 Waerntges S, Klingel K, Weigert C, Fillon S, Buck M, Schleicher E, Rodemann HP, Knabbe C, Kandolf R, Lang F: Excessive transcription of the human serum and glucocorticoid dependent kinase hsgk1 in lung fibrosis. Cell Physiol Biochem 2002;12:135-142. 


\section{Cellular Physiology Cell Physiol Biochem 2015;36:937-946 \begin{tabular}{l|l} 
DOI: 10.1159/000430268 & (C) 2015 S. Karger AG, Basel
\end{tabular} www.karger.com/cpb \\ Deng et al.: PDGF and TGFß1 Regulate ARDS-Associated LF}

9 Siegmann N, Worbs D, Effinger F, Bormann T, Gebhardt M, Ulrich M, Wermeling F, Muller-Hermelink E, Biedermann T, Tighe M, Edwards MJ, Caldwell C, Leadbetter E, Karlsson MC, Becker KA, Gulbins E, Doring G: Invariant natural killer $\mathrm{t}$ (inkt) cells prevent autoimmunity, but induce pulmonary inflammation in cystic fibrosis. Cell Physiol Biochem 2014;34:56-70.

10 Grassme H, Carpinteiro A, Edwards MJ, Gulbins E, Becker KA: Regulation of the inflammasome by ceramide in cystic fibrosis lungs. Cell Physiol Biochem 2014;34:45-55.

11 Cao B, Guo Z, Zhu Y, Xu W: The potential role of pdgf, igf-1, tgf-beta expression in idiopathic pulmonary fibrosis. Chin Med J (Engl) 2000;113:776-782.

12 Rodriguez A, Castano M, Pena L, Sanchez MA, Nieto A, Rodriguez M: Immunocytochemical detection of growth factors (pdgf and tgf beta) in equine chronic pneumonia. Research in veterinary science 1996;60:82-87.

13 Rojas-Valencia L, Montiel F, Montano M, Selman M, Pardo A: Expression of a 2.8-kb pdgf-b/c-sis transcript and synthesis of pdgf-like protein by human lung fibroblasts. Chest 1995;108:240-245.

14 Bonner JC, Brody AR: Asbestos-induced alveolar injury. Evidence for macrophage-derived pdgf as a mediator of the fibrogenic response. Chest 1991;99:54S-55S.

15 Yang T, Chen M, Sun T: Simvastatin attenuates tgf-beta1-induced epithelial-mesenchymal transition in human alveolar epithelial cells. Cell Physiol Biochem 2013;31:863-874.

16 Demoulin JB, Essaghir A: Pdgf receptor signaling networks in normal and cancer cells. Cytokine Growth Factor Rev 2014;25:273-283.

17 Heldin $\mathrm{CH}$ : Targeting the pdgf signaling pathway in the treatment of non-malignant diseases. Journal of neuroimmune pharmacology : the official journal of the Society on NeuroImmune Pharmacology 2014;9:69-79.

18 Wu FR, Pan CX, Rong C, Xia Q, Yuan FL, Tang J, Wang XY, Wang N, Ni WL, Chen FH: Inhibition of acid-sensing ion channel $1 \mathrm{a}$ in hepatic stellate cells attenuates pdgf-induced activation of hscs through mapk pathway.

Mol Cell Biochem 2014;395:199-209.

19 Seikrit C, Henkel C, van Roeyen CR, Bokemeyer D, Eitner F, Martin IV, Boor P, Knuchel R, Meyer HE, Muller-Newen G, Eriksson U, Floege J, Ostendorf T: Biological responses to pdgf-aa versus pdgf-cc in renal fibroblasts. Nephrol Dial Transplant 2013;28:889-900.

20 Foo NP, Lin SH, Lee YH, Wu MJ, Wang YJ: Alpha-lipoic acid inhibits liver fibrosis through the attenuation of ros-triggered signaling in hepatic stellate cells activated by pdgf and tgf-beta. Toxicology 2011;282:39-46.

21 Si HF, Lv X, Guo A, Jiang H, Li J: Suppressive effect of leflunomide on rat hepatic stellate cell proliferation involves on pdgf-bb-elicited activation of three mitogen-activated protein kinases. Cytokine 2008;42:2431.

22 Borkham-Kamphorst E, van Roeyen CR, Ostendorf T, Floege J, Gressner AM, Weiskirchen R: Pro-fibrogenic potential of pdgf-d in liver fibrosis. J Hepatol 2007;46:1064-1074.

23 Adachi T, Togashi H, Suzuki A, Kasai S, Ito J, Sugahara K, Kawata S: Nad(p)h oxidase plays a crucial role in pdgf-induced proliferation of hepatic stellate cells. Hepatology 2005;41:1272-1281.

24 Borkham-Kamphorst E, Stoll D, Gressner AM, Weiskirchen R: Antisense strategy against pdgf b-chain proves effective in preventing experimental liver fibrogenesis. Biochem Biophys Res Commun 2004;321:413-423.

25 Terashima M, Mitani T, Hosokawa Y, Nariai Y, Imada K, Kageyama E, Tanigawa Y: Suppressive effect of taurine on platelet-derived growth factor (pdgf) bb-induced c-fos and c-jun mrna expressions through extracellular signal-regulated kinase (erk) in mesenchymal cell lines. J Nutr Sci Vitaminol (Tokyo) 2003;49:187-194.

26 Xiao X, Wiersch J, El-Gohary Y, Guo P, Prasadan K, Paredes J, Welsh C, Shiota C, Gittes GK: Tgfbeta receptor signaling is essential for inflammation-induced but not beta-cell workload-induced beta-cell proliferation. Diabetes 2013;62:1217-1226.

27 Allison SJ: Fibrosis: Regulation of fibrotic signalling by tgf-beta receptor tyrosine phosphorylation. Nat Rev Nephrol 2014;10:484.

28 O'Reilly S, Ciechomska M, Cant R, van Laar JM: Interleukin-6 (il-6) trans signaling drives a stat3-dependent pathway that leads to hyperactive transforming growth factor-beta (tgf-beta) signaling promoting smad3 activation and fibrosis via gremlin protein. J Biol Chem 2014;289:9952-9960. 


\section{Cellular Physiology Cell Physiol Biochem 2015;36:937-946 \begin{tabular}{l|l|l}
\hline DOI: 10.1159/000430268 & (C)15 S. Karger AG, Basel
\end{tabular} www.karger.com/cpb \\ Deng et al.: PDGF and TGFB1 Regulate ARDS-Associated LF}

29 Sun H, Harris WT, Kortyka S, Kotha K, Ostmann AJ, Rezayat A, Sridharan A, Sanders Y, Naren AP, Clancy JP: Tgf-beta downregulation of distinct chloride channels in cystic fibrosis-affected epithelia. PLoS One 2014;9:e106842.

30 Okada Y, Shirai K, Reinach PS, Kitano-Izutani A, Miyajima M, Flanders KC, Jester JV, Tominaga M, Saika S: Trpa1 is required for tgf-beta signaling and its loss blocks inflammatory fibrosis in mouse corneal stroma. Lab Invest 2014;94:1030-1041.

31 Zhang L, Li Y, Chen M, Su X, Yi D, Lu P, Zhu D: 15-lo/15-hete mediated vascular adventitia fibrosis via p38 mapk-dependent tgf-beta. J Cell Physiol 2014;229:245-257.

32 Cheng X, Gao W, Dang Y, Liu X, Li Y, Peng X, Ye X: Both erk/mapk and tgf-beta/smad signaling pathways play a role in the kidney fibrosis of diabetic mice accelerated by blood glucose fluctuation. Journal of diabetes research 2013;2013:463740.

33 Akhmetshina A, Palumbo K, Dees C, Bergmann C, Venalis P, Zerr P, Horn A, Kireva T, Beyer C, Zwerina J, Schneider H, Sadowski A, Riener MO, MacDougald OA, Distler O, Schett G, Distler JH: Activation of canonical wnt signalling is required for tgf-beta-mediated fibrosis. Nat Commun 2012;3:735.

34 Meng XM, Huang XR, Xiao J, Chen HY, Zhong X, Chung AC, Lan HY: Diverse roles of tgf-beta receptor ii in renal fibrosis and inflammation in vivo and in vitro. J Pathol 2012;227:175-188.

35 Yuan Q, Wang R, Peng Y, Fu X, Wang W, Wang L, Zhang F, Peng Z, Ning W, Hu G, Wang Z, Tao L: Fluorofenidone attenuates tubulointerstitial fibrosis by inhibiting tgf-beta(1)-induced fibroblast activation. Am J Nephrol 2011;34:181-194.

36 Ueno M, Maeno T, Nomura M, Aoyagi-Ikeda K, Matsui H, Hara K, Tanaka T, Iso T, Suga T, Kurabayashi M: Hypoxia-inducible factor-1alpha mediates tgf-beta-induced pai-1 production in alveolar macrophages in pulmonary fibrosis. Am J Physiol Lung Cell Mol Physiol 2011;300:L740-752.

37 Rodrigues Diez R, Rodrigues-Diez R, Lavoz C, Rayego-Mateos S, Civantos E, Rodriguez-Vita J, Mezzano S, Ortiz A, Egido J, Ruiz-Ortega M: Statins inhibit angiotensin ii/smad pathway and related vascular fibrosis, by a tgf-beta-independent process. PLoS One 2010;5:e14145.

38 Sumioka T, Ikeda K, Okada Y, Yamanaka O, Kitano A, Saika S: Inhibitory effect of blocking tgf-beta/smad signal on injury-induced fibrosis of corneal endothelium. Mol Vis 2008;14:2272-2281.

39 Fu K, Corbley MJ, Sun L, Friedman JE, Shan F, Papadatos JL, Costa D, Lutterodt F, Sweigard H, Bowes S, Choi M, Boriack-Sjodin PA, Arduini RM, Sun D, Newman MN, Zhang X, Mead JN, Chuaqui CE, Cheung HK, Zhang X, Cornebise M, Carter MB, Josiah S, Singh J, Lee WC, Gill A, Ling LE: Sm16, an orally active tgf-beta type i receptor inhibitor prevents myofibroblast induction and vascular fibrosis in the rat carotid injury model. Arterioscler Thromb Vasc Biol 2008;28:665-671.

40 Imanishi R, Ashizawa N, Ohtsuru A, Seto S, Akiyama-Uchida Y, Kawano H, Kuroda H, Nakashima M, Saenko VA, Yamashita S, Yano K: Gh suppresses tgf-beta-mediated fibrosis and retains cardiac diastolic function. Mol Cell Endocrinol 2004;218:137-146.

41 Akiyama-Uchida Y, Ashizawa N, Ohtsuru A, Seto S, Tsukazaki T, Kikuchi H, Yamashita S, Yano K: Norepinephrine enhances fibrosis mediated by tgf-beta in cardiac fibroblasts. Hypertension 2002;40:148154.

42 Nichols WW, Murphy DG, Cristofalo VJ, Toji LH, Greene AE, Dwight SA: Characterization of a new human diploid cell strain, imr-90. Science 1977;196:60-63.

43 Truty MJ, Urrutia R: Basics of tgf-beta and pancreatic cancer. Pancreatology 2007;7:423-435.

44 Massague J: Tgfbeta signalling in context. Nat Rev Mol Cell Biol 2012;13:616-630.

45 Xiao X, Gaffar I, Guo P, Wiersch J, Fischbach S, Peirish L, Song Z, El-Gohary Y, Prasadan K, Shiota C, Gittes GK: M2 macrophages promote beta-cell proliferation by up-regulation of smad7. Proc Natl Acad Sci U S A 2014;111:E1211-1220.

46 Ding Y, Kim SL, Lee SY, Koo JK, Wang Z, Choi ME: Autophagy regulates tgf-beta expression and suppresses kidney fibrosis induced by unilateral ureteral obstruction. J Am Soc Nephrol 2014;25:2835-2846.

47 Ding Y, Choi ME: Regulation of autophagy by tgf-beta: Emerging role in kidney fibrosis. Semin Nephrol 2014;34:62-71.

48 Ding Y, Kim JK, Kim SI, Na HJ, Jun SY, Lee SJ, Choi ME: Tgf-\{beta\}1 protects against mesangial cell apoptosis via induction of autophagy. J Biol Chem 2010;285:37909-37919.

49 Suzuki HI, Kiyono K, Miyazono K: Regulation of autophagy by transforming growth factor-beta (tgf-beta) signaling. Autophagy 2010;6:645-647. 